\title{
FAKTOR-FAKTOR YANG BERHUBUNGAN DENGAN PEMAKAIAN KONTRASEPSI KONDOM PADA PASANGAN USIA SUBUR DI WILAYAH KERJA PUSKESMAS CAMPALAGIAN
}

\author{
Reskiawati Azis ${ }^{1}$ Muliyana ${ }^{2}$ \\ Program Studi IImu Kebidanan STIKES Graha Edukasi Makassar \\ Email: reskimirha@gmail.com
}

\begin{abstract}
ABSTRAK
Tujuan penelitian: Untuk mengetahui Faktor-faktor yang berhubungan dengan Pemakaian Kontrasepsi Kondom Pada Pasangan Usia Subur Di Wilayah Kerja Puskesmas Campalagian. Metode: penelitian ini adalah penelitian survey analitik dengan pendekatan "Cross Sectional Study "dimana variabel independen dan variabel dependen dikumpulkan dalam waktu yang sama untuk mendapatkan informasi tentang beberapa faktor yang berhubungan dengan pemakaian metode kontrasepsi kondom pada pasangan usia subur (PUS). Hasil: Hasil penelitian menunjukan bahwa hasil analisis menggunakan uji Chi-square antara pengetahuan dengan rendahnya penggunaan kontrasepsi kondom diperoleh nilai $p=0,003$ (nilai $P$ value $<0,05$ ) yang berarti Ha diterima, antara efek samping dengan rendahnya penggunaan kontrasepsi kondom diperoleh nilai $p=0,002$ (nilai $P$ value $<0,05$ ) yang berarti Ha diterima, antara Paritas dengan rendahnya penggunaan kontrasepsi kondom diperoleh nilai $p=0,010$ (nilai $P$ value $>0,05$ ) yang berarti Ho ditolak. Sehingga secara statistik dianggap ada hubungan antara Pengetahuan, Efek samping dengan rendahnya penggunaan metode kontrasepsi kondom sedangkan paritas dianggap tidak ada hubungan dengan rendahnya pemakaian kontrasepsi kondom. Diskusi: keluarga berencana adalah tindakan yang membantu pasangan suami istri untuk menghindari kehamilan yang tidak diinginkan, mendapatkan kelahiran yang memang sangat diinginkan, mengatur interval diantara kehamilan, mengontrol waktu saat kelahiran dalam hubungan dengan umur suami istri serta menentukan jumlah anak dalam keluarga. Masa subur seorang wanita memilki peranan bagi terjadinya kehamilan sehingga peluang wanita melahirkan menjadi cukup tinggi. Menurut hasil penelitian usia subur seorang wanita rata-rata 15-49 tahun walaupun sebagian wanita mengalami manarche (haid pertama) pada usia 9-10 tahun. Oleh karena itu untuk mengatur jumlah kelahiran atau menjarangkan kelahiran, pasangan usia subur ini lebih di prioritaskan untuk menggunakan alat/cara KB. Simpulan: Tidak ada hubungan tingkat pengetahuan ibu, Efek samping dan Paritas dengan pemakaian kontrasepsi kondom di wilayah kerja Puskesmas campalagian. Saran: Bagi Provider KB khususnya pasangan usia subur agar secara bertahap menjadi peserta KB yang aktif lestari sehingga memberi efek langsung penurunan fertilisasi.
\end{abstract}

Kata kunci : Pemakaian Kontrasepsi Kondom, Pengetahuan, efek samping, Paritas

\section{ABSTRACT}

The research objective: To determine the factors associated with the use of contraceptive condoms in fertile aged couples in the Campalagian Community Health Center. Methods: This study is an analytical survey research with a "Cross Sectional Study" approach where the independent and dependent variables are collected at the same time to obtain information about several factors associated with the use of the condom contraceptive method in reproductive age couples (EFA). Results: The results showed that the results of the analysis using the Chi-square test between knowledge and the low use of condom contraception obtained $p$ value $=0.003$ ( $P$ value $<0.05)$, which means that $\mathrm{Ha}$ is accepted, between side effects and low use of condom contraception, the $p$ value is obtained. $=0.002$ ( $P$ value $<0.05)$, which means that $\mathrm{Ha}$ is accepted, between parity and the low use of condom contraceptives, the value of $p=$ 0.010 ( $P$ value $>0.05)$ means that Ho is rejected. So that statistically it is considered that there is a relationship between knowledge, side effects and the low use of the condom contraceptive method, while parity is considered to have no relationship with the low use of condom contraception. Discussion: family planning is an action that helps husband and wife to avoid unwanted pregnancies, get births that are very desirable, adjust the interval between pregnancies, control the time at birth in relation to the age of the husband and wife and determine the number of children in the family. The fertile period of a woman has a role in the occurrence of pregnancy so that the chances of a woman giving birth are quite high. According 
to research results, the average fertile age of a woman is 15-49 years, although some women experience manarche (first menstruation) at the age of 9-10 years. Therefore, to regulate the number of births or space births, couples of childbearing age are prioritized to use family planning methods. Conclusion: There is no relationship between maternal knowledge, side effects and parity with the use of condom contraception in the work area of the Campalagian Puskesmas. Suggestion: For family planning providers, especially couples of childbearing age, to gradually become active, sustainable family planning participants so as to have a direct effect on decreasing fertilization.

\section{Key words: Use of condom contraception, knowledge, side effects, parity}

\section{PENDAHULUAN}

Di dunia Internasional menghadapi masalah pertumbuhan pada akhir dekade 60 -an, selain mempengaruhi strategi dan praktek pembangunan ekonomi kiranya ikut mempengaruhi kebijakan terhadap masalah kependudukan. Problem pertumbuhan penduduk dengan demikian telah menjadi fokus persoalan, bahkan mengurangi angka pertumbuhan penduduk dilihat sebagai salah satu kunci dalam menyelesaikan persoalan yang lebih luas, yaitu kemiskinan dan keterbelakangan ialah karena meledaknya penduduk diseluruh dunia telah bertambah lebih dua kali lipat dalam masa satu abad. (Juliantoro. 2018)

Menurut World Health Organisation (WHO) expert committee : keluarga berencana adalah tindakan yang membantu pasangan suami istri untuk menghindari kehamilan yang tidak diinginkan, mendapatkan kelahiran yang memang sangat diinginkan, mengatur interval diantara kehamilan, mengontrol waktu saat kelahiran dalam hubungan dengan umur suami istri serta menentukan jumlah anak dalam keluarga.

Sejalan dengan cita-cita pembangunan nasional, program Keluarga Berencana bertujuan menciptakan kesejahteraan ekonomi, spiritual dan social budaya. Penduduk Indonesia melalui keluarga sehat sejahtera, agar dapat mencapai keseimbangan yang baik dengan kemampuan produksi yang tinggi. Prakarsa KB Nasional ini mengusung sejumlah manfaat bagi rakyat Indonesia terutama bagi pasangan suami istri yang mencegah kehamilan, ingin membatasi jumlah anak dan ingin sehat. (Depkes RI : 2019).

Paradigma baru program Keluarga Berencana Nasional telah diubah visinya dari mewujudkan norma keluarga kecil bahagia sejahtera (NKKBS) menjadi visi untuk mewujudkan "keluarga berkualitas tahun 2019". Keluarga yang berkualitas adalah yang sejahtera, sehat, maju, mandiri, memiliki jumlah anak yang ideal, berwawasan kedepan, bertanggung jawab, harmonis dan bertakwa kepada Tuhan Yang Maha Esa. (Saifuddin. 2017)
Berdasarkan visi dan misi tersebut, program keluarga berencana nasional mempunyai kontribusi penting dalam upaya meningkatkan kualitas penduduk. Dalam kontribusi tersebut Badan Koordinasi Keluarga Berencana Nasional (BKKBN) telah mewujudkan keberhasilannya selain berhasil menurunkan angka kelahiran dan pertumbuhan penduduk, juga terpenting adalah keberhasilan mengubah sikap mental dan perilaku masyarakat dalam upaya membangun keluarga berkualitas. (Soekaemi Soekir. 2016)

Jumlah penduduk yang besar dengan laju pertumbuhan yang tinggi merupakan masalah yang harus ditanggulangi. Untuk mencegah terjadinya ledakan penduduk dan dengan kondisi penduduk sekitar 230 juta jiwa, beban pemerintah sangat berat sehingga Badan Kependudukan Dan Keluarga Berencana Nasional (BKKBN) mengubah selogan Dua Anak Cukup Menjadi Dua Anak Lebih Baik. (Manuaba 2017)

Tingginya angka kelahiran di Indonesia menggelisahkan banyak pihak, program Keluarga Berencana (KB) dinilai berjalan lamban, hingga angka kelahiran mencapai 4,5 juta per tahun. Ledakan penduduk disadari akan berpengaruh pada ketersediaan pangan dan kualitas sumber daya manusia. Untuk menghindari dampak tersebut, pemerintah berusaha keras menekan angka kelahiran hingga dibawah 4,5 juta jiwa per tahun. Badan Koordinasi Keluarga Berencana Nasional (BKKBN) yang bertanggung jawab dibidang ini berusaha meningkatkan kinerja dengan meluncurkan program pemberian insentif bagi tenaga medis (BKKBN, 2019).

Masa subur seorang wanita memilki peranan bagi terjadinya kehamilan sehingga peluang wanita melahirkan menjadi cukup tinggi. Menurut hasil penelitian usia subur seorang wanita ratarata 15-49 tahun walaupun sebagian wanita mengalami manarche (haid pertama) pada usia 910 tahun. Oleh karena itu untuk mengatur jumlah kelahiran atau menjarangkan kelahiran, pasangan usia subur ini lebih di prioritaskan untuk menggunakan alat/cara KB. Kepala Badan Kependudukan dan Keluarga Berencana Nasional (BKKBN) Provinsi Sulawesi Barat, abdullah 
Kemma di Mamuju mengatakan pada tahun 2020 peserta KB di Sulbar mencapai 744.975 Peserta, data peserta KB itu kata dia menggunakan berbagai macam alat kontrasepsi diantaranya menggunakan IUD 26.127 akseptor (3,50\%), metode operasi wanita (MOW) 10.044 akseptor $(1,34 \%)$, metode operasi pria (MOP) 2.327 akseptor $(0,31 \%)$, Kondom 85.004 Akseptor $(11,41 \%)$, Implant $82.217 \quad(11,03 \%)$, Suntik 257.015 akseptor (34,49\%), Pill 282.241 akseptor $(37,88 \%)$. Menurut Kepala BKKBN Prov. Sulawesi Barat jika KB berhasil maka Negara tidak akan terbebani mengurus masyarakat yang hanya sedikit, itu artinya kemiskinan akan dapat ditekan, sebaliknya jika KB gagal maka negara akan terbebani dan orang-orang akan sulit mendapatkan akses pelayanan dari pemerintah dan kemiskinan akan terjadi, KB juga akan sangat menentukan baik buruknya pelayanan kesehatan yang dilakukan pemerintah di masyarakat karena keberhasilan KB dapat menekan laju pertumbuhan Penduduk . bila program KB gagal maka jumlah masyarakat yang diberikan pelayanan kesehatan akan semakin banyak jumlahnya, kalau penduduk terus bertambah pastilah pemerintah akan kewalahan dalam melakukan pelayanan kesehatan karena akan butuh anggaran besar dan jumlah tenaga medis yang banyak pula. Sebaliknya jika program KB berhasil maka dengan mudah Pemerintah akan memberikan pelayanan kesehatan dengan maksimal kepada masyarakat karena anggaran

\section{METODE}

penelitian ini adalah penelitian survey analitik dengan pendekatan "Cross Sectional Study "dimana variabel independen dan variabel dependen dikumpulkan dalam waktu yang sama untuk mendapatkan informasi tentang beberapa faktor yang berhubungan dengan pemakaian metode kontrasepsi kondom pada pasangan usia subur (PUS).

Tempat dilakukannya penelitian ini di Wilayah Kerja Puskesmas Campalagian Kabupaten Polewali Mandar. Penelitian akan dilaksanakan pada bulan Maret - April 2021. Sampel adalah Sebagian dari populasi yang mewakili suatu populasi. Sampel dalam penelitian ini adalah semua PUS yang menggunakan alat kontrasepsi kondom di Puskesmas Campalagian pada bulan Maret s/d April 2021. Pengambilan sampel menggunakan dengan teknik sampling yaitu non probability adalah teknik pengambilan sampel dimana tidak semua individu dalam populasi diberi peluang yang sama untuk dipilih menjadi anggota sampel dan tehnik pengambilan sampel masyarakat semakin kecil dibutuhkan. (Provinsi Sulawesi Barat)

Menurut data dari BKKBN Kabupaten Polewali Mandar Pengguna Alat Kontrasepsi (Alkon) selama tahun 2020 jumlah akseptor KB mencapai 424.836 peserta yaitu IUD sebanyak 14.819 akseptor $(3,48 \%)$, MOW sebanyak 8.153 , MOP sebanyak 1.922 akseptor $(1,91 \%)$, Kondom sebanyak 66.348 akseptor $(15,61 \%)$, Implan sebanyak 48.028 akseptor $(11,30 \%)$, Suntik sebanyak 128.308 akseptor $(30,20 \%)$, Pil sebanyak 157.258 akseptor $(37,01 \%)$. ( Data BKKBN Kabupaten Polewali Mandar ).

Menurut data dari tempat penelitian Puskesmas Campalagian Pengguna Alat Kontrasepsi (Alkon) selama tahun 2020 yaitu 458 akseptor yang terdiri dari IUD sebanyak 9 akseptor $(1,96 \%)$, Kondom sebanyak 60 akseptor $(13,10 \%)$, Implan sebanyak 25 akseptor $(5,45 \%)$, Suntik sebanyak 257 akseptor $(56,11 \%)$, Pil sebanyak 109 akseptor (23,79\%).

Pengguna Metode kontrasepsi non hormonal khususnya kondom dipengaruhi oleh beberapa faktor misalnya faktor pengetahuan, kualitas pelayanan, sosial budaya, dukungan istri, umur, paritas, efek samping, dan lain-lain. Hal ini lah yang melatar belakangi penulis untuk melakukan penelitian mengenai "Faktor-faktor yang berhubungan dengan Pemakaian Kontrasepsi Kondom Pada Pasangan Usia Subur Di Wilayah Kerja Puskesmas Campalagian".

menggunakan cara Purposive Sampling, yaitu teknik penentuan sampel untuk tujuan tertentu saja. (Saryono, 2018)

HASIL

Tabel 4.2 menunjukkan responden yang memilki pengetahuan kurang tentang kontrasepsi kondom sebanyak 29 orang $(55,8 \%)$ dan responden yang dianggap memilki pengetahuan baik sebanyak 23 orang $(44,2 \%)$.

Tabel 4.3 memperlihatkan bahwa sebagian besar responden memilki efek samping yang banyak pada pemakaian alat kontrasepsi kondom yaitu berjumlah 32 orang $(61,5 \%)$ dan 20 orang $(38,5 \%)$ efek samping kurang.

Tabel 4.4 memperlihatkan bahwa sebagian besar responden berersiko tinggi yaitu sebanyak 35 orang $(67,3 \%)$. Adapun yang beresiko rendah sebanyak 17 orang $(32,7 \%)$.

Tabel 4.5 memperlihatkan bahwa sebagian besar responden tidak memakai alat kontrasepsi yaitu sebanyak 30 orang $(57,7 \%)$, adapun yang memakai hanya 22 orang $(42,3 \%)$. 
Tabel 4.6 menunjukkan bahwa dari 29 orang $(55,8 \%)$ yang memilki Pengetahuan Kurang tentang kontrasepsi sebanyak 22 orang $(42,3 \%)$ yang tidak memakai dan hanya 7 orang $(13,5 \%)$ yang memakai. Sedangkan dari 23 orang $(44,2 \%)$ responden yang memilki pengetahuan baik ada 15 orang $(28,8 \%)$ yang memakai, dan 8 orang $(15,4 \%)$ yang tidak memakai.

Hasil analisis menggunakan uji Chi-square pada Pearson Chi-square antara pengetahuan dengan Pemakaian kontrasepsi kondom diperoleh nilai $p=0,003$ (nilai $P$ value $<0,05$ ) yang berarti Ho ditolak. Sehingga secara statistik dianggap ada hubungan yang bermakna antara pengetahuan dengan Pemakaian metode kontrasepsi kondom.

Tabel 4.7 menunjukkan bahwa dari 32 orang $(61,5 \%)$ yang mempunyai efek samping banyak, ada 19 orang $(36,5 \%)$ yang memakai dan yang tidak memakai hanya 13 orang $(25,0 \%)$. Sedangkan dari 20 orang responden mempunyai efek samping kurang yang tidak memakai kontrasepsi kondom sebanyak 17 orang $(32,7 \%)$ dan hanya 3 orang $(5,8 \%)$ yang memakai kontrasepsi kondom.
Hasil analisis menggunakan Uji Chi-square pada Pearson Chi-Square antara efek samping dengan Pemakaian kontrasepsi kondom diperoleh nilai $p=0,002$ (nilai $P$ value $<0,05$ ) yang berarti $\mathrm{Ha}$ diterima. Sehingga secara statistik dianggap ada hubungan yang bermakna antara efek samping dengan Pemakaian metode kontrasepsi kondom.

Tabel 4.8 menunjukkan bahwa dari 34 orang yang beresiko tinggi, responden yang tidak memakai kontrasepsi kondom sebanyak 24 orang $(46,2 \%)$ dan yang memakai sebanyak 10 orang $(19,2 \%)$, sedangkan dari 18 orang beresiko rendah, responden yang memakai kontrasepsi kondom sebanyak 12 orang $(23,1 \%)$, dan yang tidak memakai hanya 6 orang $(11,5 \%)$.

Hasil Analisis menggunakan uji Chi-square pada Pearson Chi-Square nilai $p=0,010$ (nilai $P$ value $<$ $0,05)$ yang berarti Ho ditolak. Sehingga secara statistik dianggap tidak ada hubungan yang bermakna antara paritas dengan penggunaan metode kontrasepsi kondom.

Tabel 4.2

Distribusi Responden Berdasarkan Pengetahuan Pemakaian Kontrasepsi Kondom Pada Pasangan Usia Subur di Wilayah Kerja Puskesmas Campalagian

\begin{tabular}{ccc}
\hline Pengetahuan & Jumlah $(\mathrm{n})$ & Persen $(\%)$ \\
\hline Baik & 23 & 44,2 \\
\hline Kurang & 29 & 55,8 \\
\hline Total & 52 & 100 \\
\hline
\end{tabular}

Sumber : Data Primer Diolah 2021

Tabel 4.3

Distribusi Responden Berdasarkan Efek Samping Pemakaian Kontrasepsi Kondom Pada Pasangan Usia Subur di Puskesmas Campalagian

\begin{tabular}{ccc}
\hline Efek Samping & Jumlah $(\mathrm{n})$ & Persen $(\%)$ \\
\hline Kurang & 20 & 38,5 \\
\hline Banyak & 32 & 61,5 \\
\hline Total & 52 & 100 \\
\hline
\end{tabular}

Sumber : Data Primer Diolah 2021

Tabel 4.3

Distribusi Responden Berdasarkan Paritas Pada Pasangan Usia Subur di Puskesmas Campalagian

\begin{tabular}{ccc}
\hline Paritas & Jumlah $(\mathrm{n})$ & Persen $(\%)$ \\
\hline Resiko Rendah & 17 & 32,7 \\
\hline Resiko Tinggi & 35 & 67,3 \\
\hline Total & 52 & 100 \\
\hline
\end{tabular}

Sumber : Data Primer Diolah 2021 
Tabel 4.5

Distribusi Responden Berdasarkan Pemakaian Kontrasepsi Kondom Pada Pasangan Usia Subur di Puskesmas Campalagian

\begin{tabular}{ccc}
\hline $\begin{array}{c}\text { Yang memakai } \\
\text { kontrasepsi kondom }\end{array}$ & Jumlah (n) & Persen (\%) \\
\hline Tidak & 30 & 57,7 \\
\hline Ya & 22 & 42,3 \\
\hline Total & 52 & 100 \\
\hline
\end{tabular}

Sumber : Data Primer Diolah 2021

Tabel 4.6

Hubungan Pengetahuan dengan penggunaan kontrasepsi kondom di Puskesmas Campalagian

\begin{tabular}{|c|c|c|c|c|c|c|c|}
\hline \multirow[t]{2}{*}{ Pengetahuan } & \multicolumn{4}{|c|}{ Kontrasepsi Kondom } & \multicolumn{2}{|c|}{ Total } & \multirow[t]{2}{*}{ 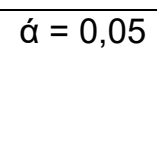 } \\
\hline & \multicolumn{2}{|c|}{ Memakai } & \multicolumn{2}{|c|}{$\begin{array}{c}\text { Tidak } \\
\text { Memakai }\end{array}$} & $\mathrm{Jml}$ & $\begin{array}{c}\text { Persen } \\
(\%)\end{array}$ & \\
\hline Kurang & 7 & 13,5 & 22 & 42,3 & 29 & 55,8 & $P=0,003$ \\
\hline Baik & 15 & 28,8 & 8 & 15,4 & 23 & 44,2 & \\
\hline Total & 22 & 42,3 & 30 & 57,7 & 52 & 100 & \\
\hline
\end{tabular}

Sumber : Data Primer di olah 2021

Tabel 4.7

Hubungan efek samping dengan penggunaan kontrasepsi kondom di Puskesmas Campalagian

\begin{tabular}{|c|c|c|c|c|c|c|c|}
\hline \multirow{2}{*}{$\begin{array}{c}\text { Efek } \\
\text { Samping }\end{array}$} & \multicolumn{4}{|c|}{ Kontrasepsi Kondom } & \multicolumn{2}{|r|}{ Total } & \multirow{2}{*}{$\alpha=0,05$} \\
\hline & \multicolumn{2}{|c|}{ Memakai } & \multicolumn{2}{|c|}{ Tidak Memakai } & $\mathrm{Jml}$ & Persen (\%) & \\
\hline Kurang & 3 & 5,8 & 17 & 32,7 & 20 & 38,5 & \\
\hline Banyak & 19 & 36,5 & 13 & 25,0 & 32 & 61,5 &, 002 \\
\hline Total & 22 & 42,3 & 30 & 57,7 & 52 & 100 & \\
\hline
\end{tabular}

Sumber : Data Primer di olah 2021

Tabel 4.8

Hubungan Pengetahuan dengan penggunaan kontrasepsi kondom di Puskesmas Campalagian

\begin{tabular}{|c|c|c|c|c|c|c|c|}
\hline \multirow{2}{*}{ Paritas } & \multicolumn{4}{|c|}{ Kontrasepsi Kondom } & \multicolumn{2}{|r|}{ Total } & \multirow{2}{*}{ 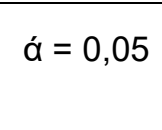 } \\
\hline & $\mathrm{Me}$ & lakai & Tida & makai & Jml & Persen (\%) & \\
\hline Resiko Rendah & 12 & 23,1 & 6 & 11,5 & 18 & 34,6 & \\
\hline Resiko Tinggi & 10 & 19,2 & 24 & 46,2 & 34 & 65,4 & $P=0,010$ \\
\hline Total & 22 & 42,3 & 30 & 57,7 & 52 & 100 & \\
\hline
\end{tabular}

Sumber : Data Primer di olah 2021

\section{DISKUSI}

Hubungan Pengetahuan dengan Pemakaian Kontrasepsi Kondom

Tingkat pengetahuan seseorang tentang kesehatan diharapkan mempunyai implikasi terhadap perilakunya dalam menggunakan pelayanan kesehatan. Tingkat pengetahuan pasangan usia subur tentang alat kontrasepsi amat penting karena pada pasangan usia subur masih rentang terhadap pemakaian kontrasepsi, sehingga jika pasangan usia subur mempunyai pengetahuan tentang metode kontrasepsi maka 
diharapkan dapat memilih salah satu alat kontrasepsi untuk digunakan, karena banyak perempuan mengalami kesulitan didalam menentukan pilihan jenis kontrasepsi, bukan hanya terbatasnya metode yang tersedia tetapi juga karena ketidaktahuan mereka tentang persyaratan dan keamanan metode kontrasepsi tersebut. Oleh karena itu peningkatan pengetahuan tentang kontrasepsi sangatlah penting bagi seorang akseptor dalam menentukan pilihannya karena jika terjadi efek samping atau keadaan tidak diinginkan ibu tahu apa yang harus dilakukannya, hal ini akan mencegah terjadinya drepout sehingga tercipta kondisi KB yang mandiri dan berkualitas sesuai dengan Visi dan Misi BKKBN dalam rangka mensejahterakan masyarakat Indonesia. (BKKBN, 2019).

Berdasarkan hasil penelitian menunjukkan bahwa dari 29 orang $(55,8 \%)$ yang memilki pengetahuan kurang tentang kontrasepsi sebanyak 22 orang $(42,3 \%)$ yang tidak memakai dan hanya 7 orang $(13,5 \%)$ yang memakai. Sedangkan dari 23 orang $(44,2 \%)$ responden yang memilki pengetahuan baik ada 15 orang $(28,8 \%)$ yang memakai, dan 8 orang $(15,4 \%)$ yang tidak memakai.

Hasil analisis menggunakan uji Chi-square pada Pearson Chi-square antara pengetahuan dengan Pemakaian kontrasepsi kondom diperoleh nilai $p=0,003$ (nilai $P$ value $<0,05$ ) yang berarti $\mathrm{Ha}$ diterima. Sehingga secara statistik dianggap ada hubungan yang bermakna antara pengetahuan dengan Pemakaian metode kontrasepsi kondom.

Hal ini Sejalan dengan penelitian yang dilakukan oleh Arganiati Yunast Iriyanto tahun 2019, bahwa ada hubungan antara tingkat pengetahuan dengan pemakaian kontrasepsi kondom. Penelitian serupa yang dilakukan oleh Dwi Mardiantari tahun 2017 di desa Besole, Kecamatan Bayan, Kabupaten Purworejo, bahwa ada hubungan tingkat pengetahuan ibu dengan pemakaian kontrasepsi kondom.

Menurut analisa peneliti bahwa pengetahuan sangat berpengaruh dengan pemakaian kontrasepsi kondom disebabkan karena rendahnya pengetahuan akseptor terkait dengan efek samping, cara kerja, efektivitas, keuntungan, kerugian, dan cara penggunaan kontrasepsi kondom. Sehingga akseptor tidak memilki minat untuk memakai kontrasepsi kondom dan lebih cenderung memilih alat kontrasepsi selain kondom.

Hubungan Efek Samping dengan Pemakaian Kontrasepsi Kondom
Efek samping adalah akibat atau gejala yang timbul, baik secara langsung maupun tidak langsung, disamping proses atau tujuan utamanya contoh efek samping dari pemakaian suatu obat. Efek samping potensial suatu metode kontrasepsi akan mempengaruhi kehidupan partisipan KB dan hal ini tentunya membuat wanita maupun pria sebagai partisipan KB harus menentukan pilihan kontrasepsi yang sesuai dan cocok untuk digunakan. Apabila efek samping dapat diatasi oleh pengguna alat kontrasepsi maka kemungkinan alat kontrasepsi tersebut tetap dipertahankan, sebaliknya apabila efeksamping tersebut terasa berat dan sangat mengganggu maka pemakai cenderung untuk melepaskan alat kontrasepsitersebut. (kamus besar kedokteran, 2019).

Hasil penelitian menunjukkan bahwa dari 32 orang $(61,5 \%)$ yang mempunyai efek samping banyak, ada 19 orang $(36,5 \%)$ yang memakai dan yang tidak memakai hanya 13 orang $(25,0 \%)$. Sedangkan dari 20 orang responden mempunyai efek samping kurang yang tidak memakai kontrasepsi kondom sebanyak 17 orang $(32,7 \%)$ dan hanya 3 orang $(5,8 \%)$ yang memakai kontrasepsi kondom.

Hasil analisis menggunakan Uji Chi-square pada Pearson Chi-Square antara efek samping dengan Pemakaian kontrasepsi kondom diperoleh nilai $p=0,002$ (nilai $P$ value $<0,05$ ) yang berarti $\mathrm{Ha}$ diterima. Sehingga secara statistik dianggap ada hubungan yang bermakna antara efek samping dengan Pemakaian metode kontrasepsi kondom.

Hal ini sejalan dengan penelitian yang dilakukan oleh Taufani 2017 di Wilayah kerja Puskesmas Kota, Kecamatan Dompu, Kabupaten Dompu Provinsi NTT yang menyimpulkan bahwa ada hubungan bermakna antara Efek samping dan pemakaian kontrasepsi kondom. Penelitian Serupa yang dilakukan oleh Mira Natalia tahun 2018 di Wilayah Kerja Puskesmas Kabawo Kabupaten Muna, bahwa ada hubungan antara efek samping dengan Pemakaian metode kontrasepsi Kondom.

Menurut analisa peneliti Efek samping sangat berpengaruh dengan pemakaian kontrasepsi kondom disebabkan karena kurangnya informasi yang diperoleh akseptor baik dari tenaga kesehatan maupun dari teman terdekat yang mengetahui tentang efek samping dari kontrasepsi kondom, sehingga akseptor tidak memilki keberanian untuk memakai kontrasepsi kondom karena akan berdampak pada kegagalan dan pada akhirnya akseptor akan berhenti (drop out) dari penggunaan kontrasepsi. 
Hubungan Paritas dengan Pemakaian Kontrasepsi Kondom

Paritas adalah jumlah persalinan yang pernah dialami oleh ibu baik lahir maupun lahir mati, tapi tidak termasuk abortus. Untuk menyelamatkan ibu dan anaknya perlu pengaturan jarak kelahiran. Paritas 1-2 merupakan paritas yang paling aman meminimalkan komplikasi yang terjadi pada ibu. Paritas $\geq 3$ mempunyai resiko yang tinggi dan dapat ditangani dengan obsetertric yang lebih baik dengan keluarga berencana. (Winkjosastro H. 2018).

Hasil penelitian menunjukkan bahwa dari 34 orang beresiko tinggi, responden yang tidak memakai kontrasepsi kondom sebanyak 24 orang $(46,2 \%)$ dan yang memakai sebanyak 10 orang $(19,2 \%)$, sedangkan dari 18 orang yang beresiko rendah, responden yang memakai kontrasepsi

\section{SIMPULAN}

1. Ada hubungan tingkat pengetahuan ibu dengan pemakaian kontrasepsi kondom di wilayah kerja Puskesmas campalagian, dengan berdasarkan hasil Analisa data didapatkan $p=0,003$.

2. Ada hubungan antara efek samping dengan rendahnya penggunaan metode metode kontrasepsi kondom di wilayah kerja Puskesmas Campalagian, dengan berdasrkan hasil Analisa data didapatkan $p=0,002$

3. Tidak ada hubungan antara Paritas dengan rendahnya penggunaan metode metode kontrasepsi kondom di wilayah kerja Puskesmas Campalagian, dengan berdasrkan hasil Analisa data didapatkan $p=0,010$.

\section{SARAN}

Berdasarkan hasil penelitian yang telah dilakukan, dengan ini dapat diberikan saran kepada pihak yang terkait :

1. Bagi Provider KB khususnya pasangan usia subur agar secara bertahap menjadi peserta $\mathrm{KB}$ yang aktif lestari sehingga memberi efek langsung penurunan fertilisasi.

2. Bagi Pelaksana pelayanan Keluarga Berencana supaya sebelum pemberian penggunaan kontrasepsi kondom perlu adanya Pemberian informasi yang lebih akurat mengenai efek Samping, cara kerja, Efektivitas, Keuntungan, kerugian, dan cara penggunaan kondom itu sendiri. Sehingga masyarakat memiliki minat untuk menjadi akseptor KB Kondom. kondom sebanyak 12 orang $(23,1 \%)$, dan yang tidak memakai hanya 6 orang $(11,5 \%)$.

Hasil Analisis menggunakan uji Chi-square pada Pearson Chi-Square nilai $p=0,010$ (nilai $P$ value $>0,05)$ yang berarti Ho ditolak. Sehingga secara statistik dianggap ada tidak ada hubungan yang bermakna antara paritas dengan penggunaan metode kontrasepsi kondom.

Hal ini Sejalan dengan penelitian yang dilakukan oleh Rahajeng Putriningrum di Bidan Praktek Swasta Ruvina Esien Surakarta tahun 2016, bahwa tidak ada hubungan yang bermakna antara Paritas dengan pemakaian kontrasepsi kondom. Penelitian serupa dilakukan oleh Muhammad Irwan Rizali di Kelurahan Mattoangin Kecamatan Mariso Kota Makassar Tahun 2017 yang menyimpulkan bahwa tidak ada hubungan bermakna antara Paritas dengan pemakaian kontrasepsi kondom.

\section{REFERENSI}

BKKBN. 2020. Profil Keluarga Berencana dan Kependudukan. Kabupaten Polewali Mandar

Dinkes. 2019. Profil Keluarga Berencana dan Kependudukan. Povinsi Sulawesi Barat

Handayani Sri. 2017. Pelayanan KB. Pustaka Rihama. Yogyakarta.

Hartanto, H. 2015. Keluarga Berencana dan Kontrasepsi. Cetakan III. Pustaka Sinar Harapan. Jakarta.

Manuaba IBG, Manuaba IAC, Fajar Manuaba IBG. 2017. IImu Kebidanan, Penyakit Kandungan dan KB untuk Pendidikan Bidan. EGC. Jakarta

Noviawati Dyah SA. 2016. Panduan Lengkap Pelayanan KB. Mitra Cendikia. Yogyakarta.

Prawirohardjo S. 2017. IImu Kebidanan. Yayasan Bina Pustaka Sarwono Prawirohardjo. Jakarta.

Saifuddin AB. 2017. Buku Panduan Praktis Pelayanan Kontrasepsi. Edisi 2 ke dua Yayasan Bina Pustaka Sarwono Prawirohardjo. Jakarta

Sujiyatini. 2016. Panduan Lengkap Pelayanan KB. Mitra Cendikia. Yogyakarta.

Soekaemi Soekir. 2016. Buku Panduan Praktis Pelayanan Kontrasepsi. Edisi 2 Yayasan Bina Pustaka Sarwono Prawirohardjo. Jakarta 
Wiknjosastro, Hanifa, dkk. 2015. Ilmu Kebidanan. Yayasan

\author{
Pustaka.
}

Prawihardjo. Jakarta. 